\title{
Intraosseous stress distribution and bone interaction during load application across the canine elbow joint: A preliminary finite element analysis for determination of condylar fracture pathogenesis in immature and mature dogs
}

\author{
Beatrice Böhme ${ }^{\mathrm{a}}$, Vinciane d'Otreppe ${ }^{\mathrm{b}}$, Jean-Phillippe Ponthot ${ }^{\mathrm{b}}$, Marc Balligand ${ }^{\mathrm{a}, *}$ \\ a Department of Clinical Sciences, Small Animal Surgery Service, Faculty of Veterinary Medicine, University of Liège, Belgium \\ ${ }^{\mathrm{b}}$ Department of Aerospace and Mechanics, University of Liège, Belgium
}

\section{A R T I C L E I N F O}

\section{Article history:}

Received 9 September 2015

Received in revised form 17 March 2016

Accepted 28 March 2016

\section{Keywords:}

Finite element analysis

Condylar fracture

Fracture pathogenesis

Elbow

Dog

\begin{abstract}
A B S T R A C T
Distal humeral fractures are common fractures especially in immature small breed dogs. The pathogenesis is still unknown. For this study, a three- dimensional bone model of the canine elbow was created and finite element analysis performed in order to determine the relationship between fracture type and bone interactions. Fused and non-fused humeral condyles were considered. A failure criterion was implemented to simulate the pathogenesis until fracture. Our study results confirm the clinical observation that lateral condylar fracture is the most common fracture type, implying interaction with the radius. Medial and Y-fractures are less common and occur always in interaction with the ulna whereas the radius causes lateral condylar fracture. Additionally, the fracture type is sensitive to bone positioning during trauma. The pathogenesis of distal humeral fractures is more complex than generally reported in the literature.
\end{abstract}

(c) 2016 Elsevier Ltd. All rights reserved.

\section{Introduction}

Distal humeral condylar fractures account for approximately $50 \%$ of all humeral fractures (Bardet et al., 1983; Brinker et al., 2006). They are classified as simple and comminuted supracondylar, lateral and medial condylar and intercondylar or bicondylar ( $\mathrm{T}$ - and Y-) fractures. Lateral condylar fractures occur most often (56-67\%), compared to 33-35\% bicondylar and 4-16\% medial condylar fractures (Bardet et al., 1983; Cockett et al., 1985; Denny 1983; Rorvik 1993; Vannini et al., 1988a, b, 2007). These types of fracture are reported in dogs of any age (Knight 1959; Rorvik 1993; Shuttleworth 1938), but predominantly in young dogs less than one year in age (Guille et al., 2004; Schebitz et al., 1976; Vannini et al., 1988a, b) with a peak incidence around four months old when ossification of the humeral condyle is not yet completed (Cockett et al., 1985; Denny 1983; Knight 1959). Lateral condylar fractures are often described as the result of minor, indirect trauma (Anderson et al., 1990; Guille et al., 2004; Rorvik 1993; Vannini et al., 1988a,b).

A breed predisposition seems to be present in Yorkshire Terriers (Cockett et al., 1985; Rorvik 1993), French and English Bulldogs (Rorvik 1993), Pinscher (Rorvik 1993), Springer Spaniels, Cocker Spaniels (Vannini et al., 1988a, b) and Cavalier King Charles Spaniels (Denny

\footnotetext{
* Corresponding author.

E-mail address: marc.balligand@ulg.ac.be (M. Balligand).
}

1983), whereas the incidence of condylar fractures in giant breeds is low (Cockett et al., 1985; Denny 1983). Incomplete ossification of the humeral condyle is an important risk factor for condylar humeral fractures in adults and has been described in Cocker Spaniels (Kaderly 1994; Marcellin-Little et al., 1994; Meyer-Lindenberg et al., 2002), Labrador Retrievers (Robin 2001), Rottweilers (Rovesti et al., 1998) and English Pointer dogs (Gnudi et al., 2005).

Though a number of theories have been proposed concerning the condylar fracture pathogenesis, there is no evidence in the literature for the influence of the elbow position when fracture occurs. Various authors describe condylar humeral fractures as occurring during axial loading with proximal displacement of the radius towards the weightbearing lateral humeral condyle (Walker \& Hickman; Shuttleworth 1938; Knight 1959; Schebitz et al. 1976; Cockett et al., 1985). For bicondylar fractures, Shuttleworth proposed a mechanism where the medial condyle fractures first, followed by the lateral condyle (Shuttleworth 1938). Two different hypotheses have been drawn from our observations. Most elbow fractures occur after a fall from a height. Upon impact, ground forces travelling from distal to proximal through the front limb may possibly cause the elbow to flex until the caudal aspect of the ulna touches the ground, with the ulnar notch acting then as a shim in between the two condyles, pushing them apart. Another scenario would be the very sudden bracing of the elbow joint in full extension upon impact of the front paw on the ground due to a strong reflex 
contraction of the triceps muscle, hence making the radial head impact the distal lateral humeral condyle until fracture. Both scenarios may be possible in different varus-valgus positions of the elbow that could influence the fracture type: lateral, medial or bicondylar.

The objective of the three-dimensional finite element analysis was to determine the intraosseous stress distribution in the distal humerus after ground contact of the limb according to bone positioning at the moment of fracture.

\section{Materials and methods}

\subsection{Specimen}

Two pairs of canine forelimbs were harvested from 4 month old Beagle dogs weighing 7-7.5 kg and euthanised for reasons unrelated to this study. Humeri were cut at the level of the humeral and radial mid-diaphysis. Soft tissues were removed, but collateral ligaments, articular capsule and muscles directly surrounding the elbow joint remained in place. Standard mediolateral and craniocaudal elbow radiographs were taken for each specimen to confirm skeletal immaturity and to exclude radiographic visible elbow diseases.

\subsection{Computed tomography}

High resolution computed tomographic scans (CT) were performed in $0.7 \mathrm{~mm}$ sections on the elbows, from the distal third of the humerus to the proximal third of the radius and ulna, while placed in a flexion angle of $150^{\circ}$, at $-10^{\circ}, 0^{\circ}$ and $+10^{\circ}$ of endo-/exorotation (Siemens Somatron 16-slice, Germany). Each section had a resolution of $0.115 \mathrm{~mm} \times 0.115 \mathrm{~mm}$ and dimensions of $512 \times 512$ pixels.

\subsection{Finite element analysis}

Computed tomographic scans were segmented using Slicer 3D software (Pieper et al., 2004) to delineate radius, ulna, and humerus, cortical, trabecular bone and cartilage of the area of interest. Based on these structure identifications, a three-dimensional model of the canine elbow was constructed using an automatic procedure described in (D'Otreppe et al., 2010; D'Otreppe et al., 2012). Models of immature and mature elbows were derived from the same CT images to facilitate comparison between both scenarios. The model was simplified by considering the unit of radius and ulna as a rigid body, whereas the humerus was defined as a deformable structure.

\subsubsection{Models 1 and 2 (mature dog)}

The numerical canine elbow model was built using a mesh for the humerus including trabecular and cortical bone: In Model 1, the mesh of cortical bone was built using 26841 nodes. The trabecular bone was not considered and the space normally filled by it was left empty for simplification. In Model 2, the humerus was meshed using 9440 nodes for cortical bone and 5177 nodes for the trabecular bone. For radius and ulna a surface mesh of 1336 (radius) and 1657 nodes (ulna) was created using the external physical boundaries of the bone.

\section{Table 2}

Results of Simulation 1: tested conditions with different FEA, AbAdA and RA combinations: interaction of bones and stress-strain dependent resultant expected fracture type by von Mises stress field interpretation.

\begin{tabular}{|c|c|c|c|c|}
\hline $\begin{array}{l}\text { Flexion } \\
\text { angle }\left({ }^{\circ}\right)\end{array}$ & $\begin{array}{l}\text { Abduction }(+) \\
\text { Adduction }(-)\end{array}$ & $\begin{array}{l}\text { Endorotation }(+) \\
\text { Exorotation }(-)\end{array}$ & $\begin{array}{l}\text { Bone } \\
\text { contact to }\end{array}$ & $\begin{array}{l}\text { Fracture } \\
\text { type }\end{array}$ \\
\hline 60 & 0 & 0 & Ulna & Lateral \\
\hline 60 & -20 & 0 & Ulna & Lateral \\
\hline 60 & 20 & 0 & Ulna & Medial \\
\hline 60 & 0 & +10 & Ulna & Y \\
\hline 60 & -20 & +10 & Ulna & $\begin{array}{l}\text { Y or } \\
\text { Lateral }\end{array}$ \\
\hline 60 & 20 & +10 & Ulna & Medial \\
\hline 60 & 0 & -10 & Ulna & Lateral \\
\hline 60 & -20 & -10 & Ulna & Lateral \\
\hline 60 & 20 & -10 & Ulna & Lateral \\
\hline 130 & 0 & 0 & Ulna & Medial \\
\hline 130 & -20 & 0 & $\begin{array}{l}\text { Radius + } \\
\text { Ulna }\end{array}$ & Lateral \\
\hline 130 & 20 & 0 & Ulna & $\begin{array}{l}\text { Medial or } \\
\mathrm{Y}\end{array}$ \\
\hline 130 & 0 & +10 & Radius & Lateral \\
\hline 130 & -20 & +10 & Radius & Lateral \\
\hline 130 & 20 & +10 & $\begin{array}{l}\text { Radius }+ \\
\text { Ulna }\end{array}$ & $\begin{array}{l}\text { Y or } \\
\text { Medial }\end{array}$ \\
\hline 130 & 0 & -10 & Radius & Lateral \\
\hline 130 & -20 & -10 & Radius & Lateral \\
\hline 130 & 20 & -10 & Radius & Lateral \\
\hline 150 & 0 & 0 & $\begin{array}{l}\text { Radius + } \\
\text { Ulna }\end{array}$ & Lateral \\
\hline 150 & -20 & 0 & Ulna & Lateral \\
\hline 150 & 20 & 0 & Ulna & Medial \\
\hline 150 & 0 & +10 & Ulna & Lateral \\
\hline 150 & -20 & +10 & Ulna & Lateral \\
\hline 150 & 20 & +10 & Ulna & $\mathrm{Y}$ \\
\hline 150 & 0 & -10 & Radius & Lateral \\
\hline 150 & -20 & -10 & Radius & Lateral \\
\hline 150 & 20 & -10 & Radius & Lateral \\
\hline
\end{tabular}

Mechanical properties applied are listed in Table 2 (Kaneps et al., 1997). Trabecular and cortical bones were considered isotropic and homogenous linear elastic materials (Polikeit et al., 2007) (See Table 1).

In Model 1 no failure criterion was applied. As bone is weaker in tension than in compression, the modified Mohr-Coulomb failure criterion (Keyak et al., 2000; Shigley et al., 1989) was chosen to mimic fracture behaviour in Model 2.

\subsubsection{Model 3 (immature dog)}

To evaluate immature conditions with non-fused condyles or incomplete ossification of the condyles, the segmentation of the humerus was further refined: cortical bone, trabecular (diaphyseal and epiphyseal) bone within the medullary cavity and the cartilaginous growth plate were all given consideration (see Figs. 1 and 2). The numerical mesh was built using 9440 nodes for the cortical bone, 12,626 nodes for trabecular bone and 297 nodes for cartilage. Similar to Model 2, the modified Mohr-Coulomb failure criterion (Keyak et al., 2000; Shigley et al., 1989) was applied to model fracture behaviour.

Table 1

Material properties of bone used for the finite element analysis (Kaneps et al., 1997).

\begin{tabular}{|c|c|c|c|}
\hline & Young's modulus (MPa) & Poisson's ratio & Failure stress (MPa) \\
\hline \multirow[t]{3}{*}{ Cortical bone } & Long.: 2660 & Long.: 0.3 & Compression: 186 \\
\hline & Trans.: 1596 & Trans.: 0.3 & Tension: 93 \\
\hline & Shear: 570 & & \\
\hline \multirow[t]{2}{*}{ Epiphyseal trabecular bone } & 2110 & 0.3 & Compression: 21 \\
\hline & & & Tension: 10.5 \\
\hline \multirow[t]{2}{*}{ Diaphyseal trabecular bone } & 1055 & 0.3 & Compression: 10.5 \\
\hline & & & Tension: 5.2 \\
\hline Cartilage & 1 & 0.45 & 0.015 \\
\hline
\end{tabular}




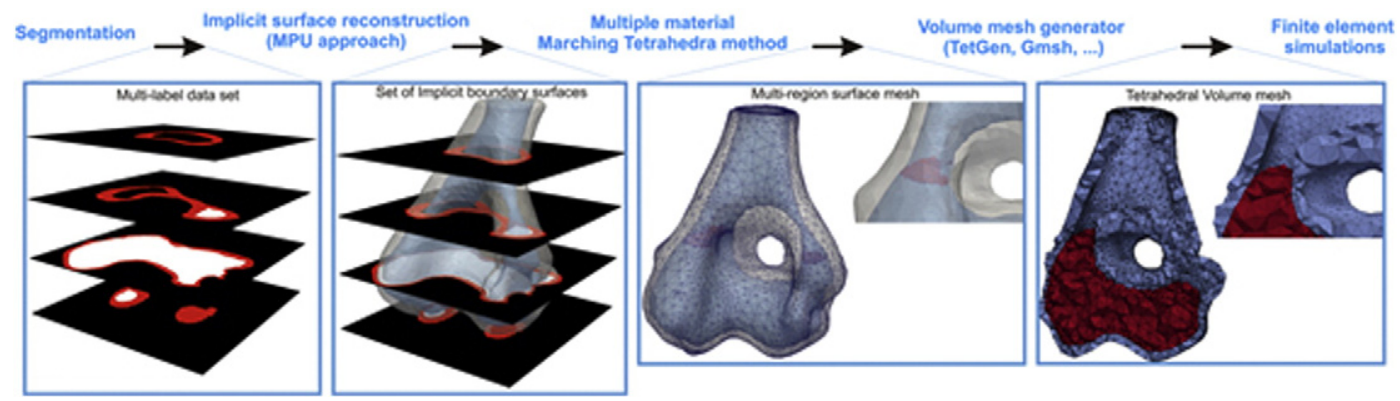

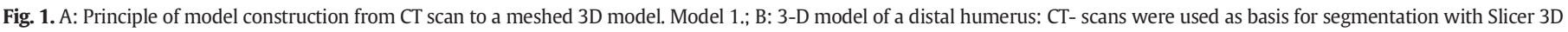
software. Cortical and trabecular bone, as well as cartilage were considered in Model 2.

\subsection{Finite element analysis simulation}

Finite element simulations were performed using the in-house finite element software, Metafor (Ponthot et al., 2000). Radius and ulna were considered as one non-deformable unit. A frictionless contact was assumed between humerus and radius and between humerus and ulna. This contact algorithm is used to model the effect of articular cartilage as a slippery surface allowing relative "sliding" between the bones. To enforce contact constraints (and prevent the bones from penetrating each other), the penalty method was used. In a simplified way, the penalty method is equivalent to setting some springs between the bodies in contact. A stiffness ' $k$ ' is attributed to each spring. The effect of the springs is to prevent the bodies in contact from penetrating each other. In practice, there is some latitude in the choice of a value of $\mathrm{k}$. Here, $\mathrm{k}$ was chosen to take into account the stiffness of the cartilage in order to reproduce a realistic contact surface between the bones.

\subsubsection{Simulation 1 (Model 1)}

Simulations were performed using Model 1 at $60^{\circ}, 130^{\circ}$ and $150^{\circ}$ of flexion-extension angle (FEA), at $-20^{\circ}, 0^{\circ}$ and $+20^{\circ}$ abduction-adduction angle (AbAdA) and in $-10^{\circ}, 0^{\circ}$ and $+10^{\circ}$ of radioulnar endo-/ exorotation angle (RA) (see Fig. 2).

The vertical displacement was applied on the radius-ulna segment. The distribution and maximal amplitude of the von Mises stresses in the distal humerus were recorded along with the contribution of the interacting bone structures. No failure criterion was implemented for this model.

The contributions of the different bones and the suspected fracture type were identified depending on distribution of the von Mises stresses within the condyles (see Table 2, Figs. 3 and 4).

\subsubsection{Simulation 2 (Models 2 and 3)}

Simulations were performed for skeletally mature (Model 2) and immature (Model 3 ) elbows at $150^{\circ}$ FEA and $60^{\circ}$ FEA configurations. Additionally a failure criterion was applied to simulate bone behaviour up to the point of bone fracture (see Section 2). Failure load, interacting bones at fracture and fracture patterns were recorded (see Table 3 and Fig. 4).

\section{Results}

\subsection{Simulation 1}

Simulation was carried out using three different variables: FEA, AbAd and RA (entailing 27 different scenarios). The interaction of bones was recorded at maximum von Mises stresses, whose distribution was evaluated to predict fracture type (see Table 2 and examples given in Fig. 3).

Overall, the ulna was the predominant interacting bone when fracture occurred. Our results show that ulna and radius could both possibly cause lateral condylar fractures $(66-70 \%, n=17$ ) (of which $47 \%$ by ulna,
A

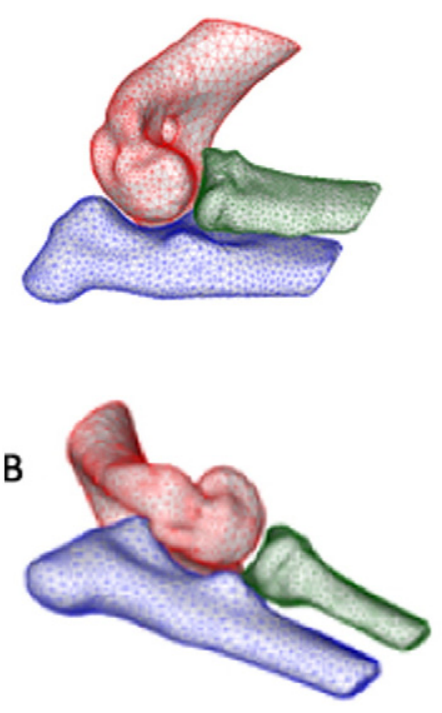

C

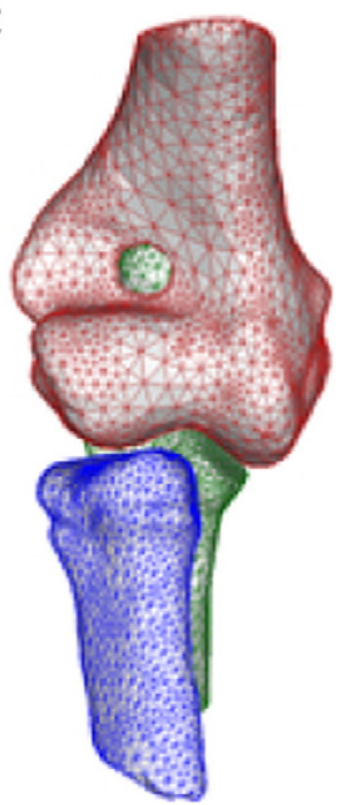

D

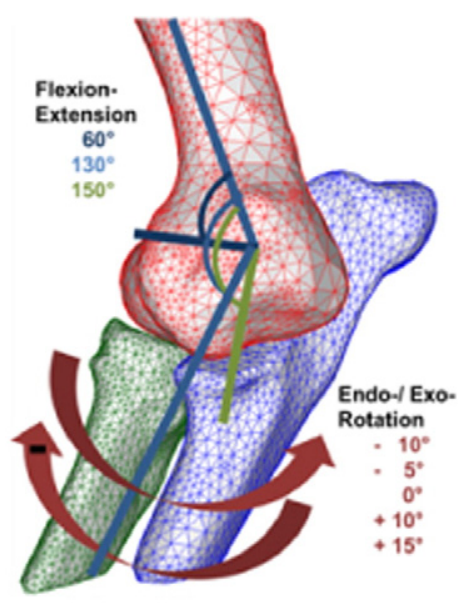

Fig. 2. Elbow positioning for FE simulation: elbow position at $60^{\circ}$ flexion (A) and $150^{\circ}$ extension (B), frontal view of $150^{\circ}$ extension (C). 

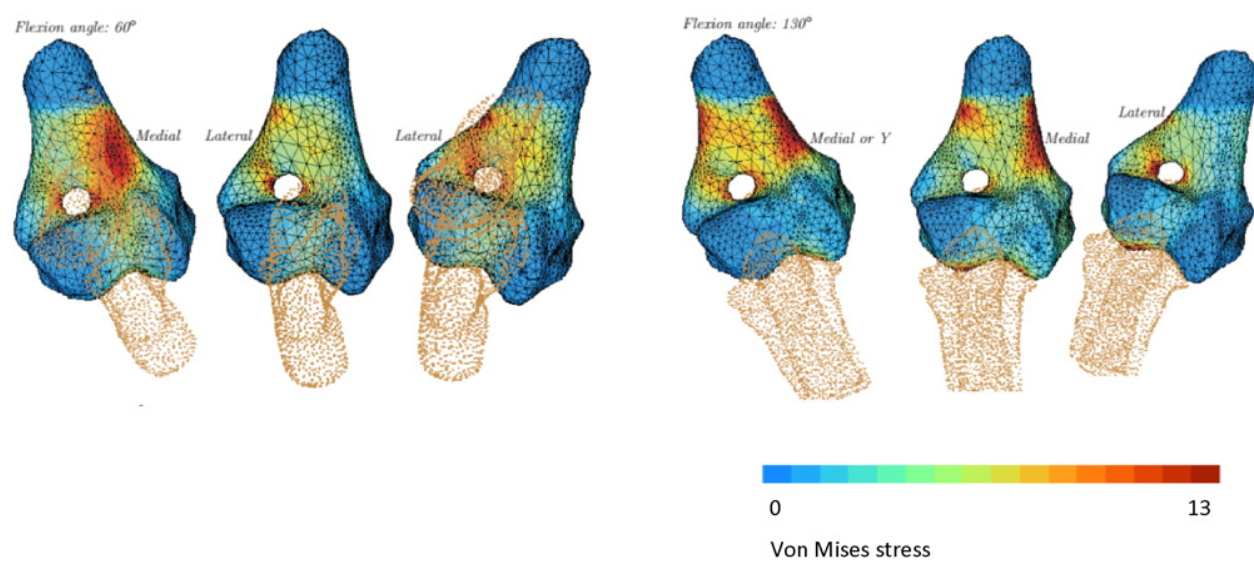

Fig. 3. Examples for von Mises stress distribution within the distal humerus at various FEA, AbAdA and RA positions. A: FEA $60^{\circ}, \mathrm{AbAd} 20^{\circ}, 0^{\circ},-20^{\circ}$.

$47 \%$ by radius, $6 \%$ by radius and ulna), whereas medial condylar fractures $(n=5)$ are predominantly caused by humeroulnar interaction ( $80 \%$ ulna, $20 \%$ radius and ulna). At $60^{\circ} \mathrm{FEA}$, the interacting bone is always the ulna, independent of AbAdA and RA.

In cases of $0^{\circ}$ of rotation and $0^{\circ} \mathrm{AbAdA}$, a humeroulnar interaction is always present before fracture occurs (at $60^{\circ}$ and $130^{\circ}$ FEA by the ulna, at $150^{\circ} \mathrm{FEA}$ by ulna and radius).

At $+10^{\circ}$ of endorotation, the ulna at $60^{\circ}$ and $150^{\circ}$ FEA is the interacting structure, whereas in $-10^{\circ}$ of exorotation, this equitation shifts more towards the radius at $150^{\circ} \mathrm{FEA}$.

At $60^{\circ} \mathrm{FEA}$, independent of AbAdA and RA, 55.5\% of the fractures are presumably lateral condylar fractures, with $44.4 \%$ medial or bilateral condylar fractures. At $130^{\circ}$ and $150^{\circ} \mathrm{FEA}, 66.6 \%$ of cases are lateral condylar fractures with the remaining 33.3\% medial or Y-fractures.

All elbows positioned in exorotation ( $-\mathrm{RA}$ ) of radius and ulna show stress distribution with suspected lateral condylar avulsion, independent of FEA and AbAdA.

At an AbAdA of $-20^{\circ}$, the fracture type suspected is a lateral condylar fracture, independent of FEA and RA (at $60^{\circ}$ FEA and $+10^{\circ}$ RA a bilateral fracture may be possible).

With the exclusion of exorotation studies $\left(-10^{\circ} \mathrm{RA}\right)$, at an AbAdA of $20^{\circ}$ mostly medial or bilateral fractures are expected. In our model, $50 \%$ of humeri positioned in endorotation $\left(+10^{\circ} \mathrm{RA}\right)$ would break the lateral condyle; the other $50 \%$ being more prone to causing medial or bilateral fractures.

\subsection{Simulation 2 (Models 2 and 3)}

At $150^{\circ} \mathrm{FEA}$, lateral condylar fractures were observed in immature and mature elbow models initiated by the radius and followed by the ulna. Observed fractures initiated on the articular surface in between both condyles and propagated towards the supracondylar foramen and the lateral epicondyle (see Fig. $4 \mathrm{~A}$ and B).

At $60^{\circ}$ FEA the fractures initiated at the external surface of the lateral and medial epicondyles simultaneously and propagated through the epicondyles in both scenarios (Models 2 and 3), but lower forces were required for immature elbows (see Fig. 4 C). These simulations confirmed the expected fracture pathogenesis, where fracture occurs in elbow extension with the radius pushing against the lateral condyle and the fracture initiating in-between both condyles propagating towards the supracondylar foramen and lateral epicondyle. With the application of higher forces, the same fracture occurs also in joint flexion with the ulna acting as a shim between the two condyles.

\section{Discussion}

Condylar fractures occur frequently in association with minimal trauma especially in young immature dogs, and adult dogs with incomplete ossification of the humeral condyles ( $\mathrm{IOH})$. The literature describes theories of the pathogenesis where axial load is applied through the radius and towards the weight-bearing lateral humeral
A

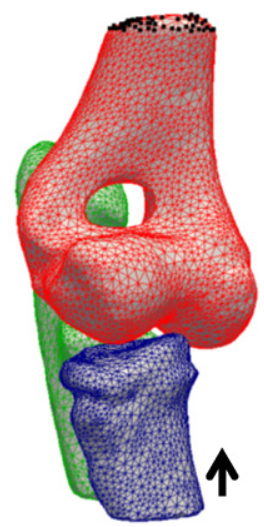

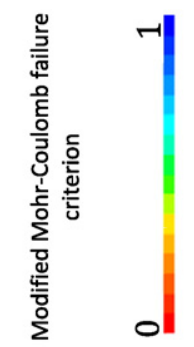

Imposed

Displacement (140 $\mathrm{mm} / \mathrm{min})$

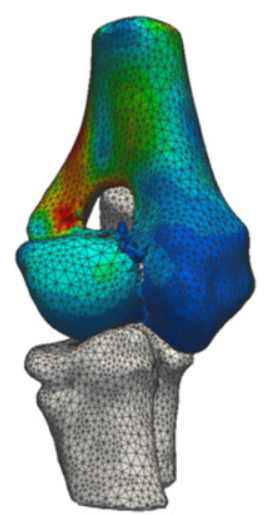

B

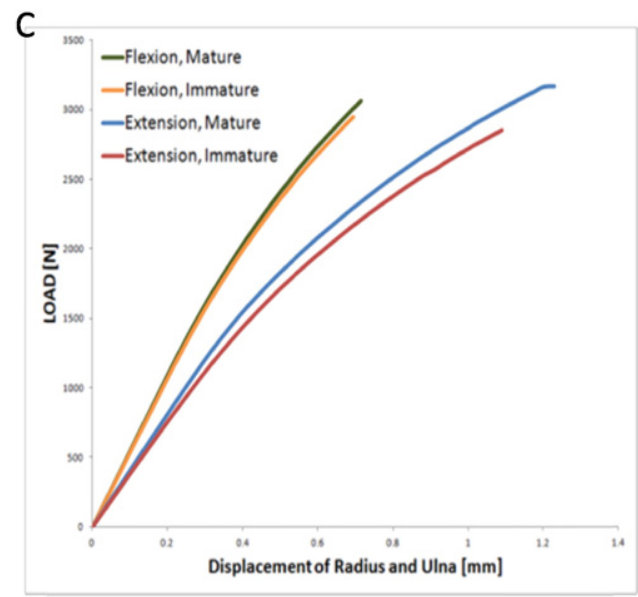

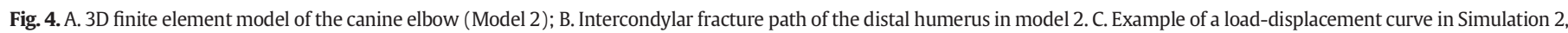
Models 1 and 2 at $60^{\circ}$ and $150^{\circ}$ FEA. 
Table 3

Results of Simulation 2 - tested conditions, interaction of bones, fracture type.

\begin{tabular}{|c|c|c|c|c|}
\hline Flexion angle $\left({ }^{\circ}\right)$ & $\begin{array}{l}\text { Mature (Model 2) } \\
\text { Immature (Model 3) }\end{array}$ & Maximum Load at failure & Bone contact to & Fracture type \\
\hline 60 & Immature & $3.5 \mathrm{kN}$ & Ulna & Bicondylar \\
\hline 60 & Mature & $3.6 \mathrm{kN}$ & Ulna & Bicondylar \\
\hline 150 & Immature & $2.49 \mathrm{kN}$ & Radius first then ulna & Lateral \\
\hline 150 & Mature & $2.61 \mathrm{kN}$ & Radius first then ulna & Lateral \\
\hline
\end{tabular}

condyle (Shuttleworth 1938; Knight 1959; Schebitz et al. 1976; Cockett et al., 1985), but to our knowledge, no study confirms the fracture pathogenesis suspected. The objective of the present three-dimensional finite element analysis was to determine the influence of the contributing bones on resulting fracture type and on fracture pathogenesis. A preliminary finite element model simulation was performed in different FEA, AbdAdd and RA (Simulation 1) combinations to evaluate stress distribution within the distal humerus according to elbow positioning. Although no failure criterion was applied, the von Mises stress distribution gives a good indication for the area of a possible fracture line. In a second step a failure criterion was applied and bone structures were refined (Models 2 and 3). Non-fused and fused humeral condyles were compared in flexion and extension (Simulation 2). Overall, the finite element simulation study performed showed that the pathogenesis of condylar fractures is likely to be more complex than what has been described in the literature to date (Bardet et al., 1983; Cockett et al., 1985; Denny 1983; Rorvik 1993; Vannini et al., 1988a, b, 2007). As seen in clinical observations, the highest likelihood was the lateral condylar fracture (clinics 56-67\%, finite element analysis $66 \%-70 \%$ of the time). Bilateral fractures were expected in $7-18 \%$ and medial condylar fractures in $18.5-26 \%$ of all scenarios tested (clinical frequency $33-$ $35 \%$ and 4-16\% respectively)(Bardet et al., 1983; Cockett et al., 1985; Denny 1983; Rorvik 1993; Vannini et al., 1988a, b, 2007).

The ulna articulates with the central part of the distal humerus and may cause lateral, medial or bicondylar fractures, whereas the radius articulates with the lateral humeral condyle and causes lateral condylar fractures. In a $60^{\circ} \mathrm{FEA}$, the ulna is acting as a shim in between the two condyles and pushing them apart, therefore at this FEA the only interacting bone in this simulation was the ulna. Endo- and exorotation and abduction and adduction of the radio-ulnar bones additionally influence the stress-strain distribution within the distal humerus and contribute to the pathogenesis of condylar fractures of the humerus. All elbows positioned in exorotation ( $-\mathrm{RA})$ of radius and ulna show stress distribution with expected lateral condylar avulsion, independent of FEA and AbAdA. Fractures may appear in extension or flexion, but require smaller loading to appear in extension or for unfused humeral condyles, as it is the case in immature animals, or in cases of incomplete ossification of the humeral condyles.

Finite element modelling and simulation still requires several simplifications. These simplifications influence results and need to be addressed in future studies.

Our study design focused on the distal humerus and proximal radius and ulna, forming the elbow joint. Adjacent bone parts, muscles and ligaments were excluded. Even though ground forces could vary according to the position of the paw upon impact with the ground, we have assumed that, whatever the position, muscle forces would successfully brace the numerous distal joints of the front leg (interphalyngeal, metacarpo-phalangeal, carpo-metacarpal joints) in order to allow ground forces, capable of breaking the distal humerus, to reach the elbow. But the creation of a three-dimensional model (multi body system) including bones and soft tissues is extremely complex and numerous data are still missing. Further studies will address this topic.

Radius and ulna were considered as a united non-deformable unit, modelled by the surface lining. Additionally, the bones in the radiusulna unit were not allowed to articulate between one another during the simulation. As we were mainly focused on the humeral condyles, we considered this limitation as acceptable.

The configuration of the humerus was adapted according to the needs for each simulation: In Model 1, the trabecular bone was not considered, but as we were mainly interested in the stresses occurring within the cortical bone, the simplification was considered acceptable.

In Model 2, the humerus was divided into its cortical and trabecular parts with both condyles considered to be fused (continuous cortical lining), whereas in Model 3 a growth plate and a cartilaginous plane in between the two condyles was included in the model. In reality, bone is a biologic non-homogenous material composed of both cortical and trabecular bone and cartilaginous material in growing animals, all of which are formed by different cells, fibres and minerals. Additionally the proportion of these ingredients varies within the bone according to various factors like breed, age, location and nutrition. Therefore bone is far from being homogeneous, but as a simplification of nature was required for our modelling, it was considered homogeneous and transversely isotropic. The anisotrophy of the bone was taken into account by assuming that all fibres lie parallel to the longitudinal axis of the humerus and, therefore, the Young's modulus in the direction of the fibres is higher than in the transverse direction (transverse isotropic, orthotropic). To create a more realistic model, analysing the fibre alignment and bone density along the whole bone would be required.

Satisfying research on mechanical properties of canine bone is still missing. As distinct elasticity and strength properties should be used for immature and adult dog models, further research is required to provide these data. Moreover, we used a linear elastic model whereas bones are generally considered as viscoelastic. To our knowledge, no failure criterion has been published for canine bone to date and therefore, the modified Mohr-Coulomb failure criterion was applied (Keyak et al., 2000). This failure criterion is a human bone failure criterion driven by stress, independent of its direction within the net of nodes. It changes with age, nutrition, anatomy and bone density. Other failure criteria have also been investigated, but were not considered any more suitable for our study. A better choice for modelling fractures would be a strain failure criterion, as bone breaks in tension. Therefore further studies are currently being carried out to determine the deformation dependent failure criterion of canine bone. In the future, this failure criterion will be used for finite element analysis and might allow a more realistic model of bone behaviour.

Despite these limitations, our study results confirm the clinical observation that lateral condylar fracture is the most common fracture type. Medial and Y- fractures are less common and occur due to humeroulnar interaction, whereas the radius causes lateral condylar fractures. Additionally, fracture type may be sensitive to bone positioning during trauma. We conclude from our results that the pathogenesis of distal humeral fractures is more complex than reported to date.

\section{Conflict of interest statement}

None of the authors of this paper has a financial or personal relationship with other people or organisations that could inappropriately influence or bias the content of the paper. 


\section{References}

Anderson, T.J., Carmichael, S., Miller, A., 1990. Intercondylar humeral fracture in the dog: a review of 20 cases. J. Small Anim. Pract. 31, 437-442.

Bardet, J., Hohn, R., Rudy, R.L., Olmstead, M.L., 1983. Fractures of the humerus in dogs and cats: a retrospective study of 130 cases. Vet. Surg. 12, 73-77.

Brinker, W., Piermattei, D., Flo, L., Dechamp, C., 2006. Handbook of Small Animal Orthopedics and Fracture Treatment. fourth ed. Elsevier, Saunders, pp. 297-320.

Cockett, P.A., Clayton-Jones, D.G., 1985. The incidence of humeral condylar fractures in the dog: a survey of 79 cases. J. Small Anim. Pract. 26, 437-444.

Denny, H., 1983. Condylar fractures of the humerus in the dog. A review of 133 cases. J. Small Anim. Pract. 24, 185-197.

D'Otreppe, V., Boman, R., Ponthot, J.P., 2010. Smooth multiple-region mesh generation for biomedical applications. ECCM 2010, 4th European Conference on Computational Mechanics http://hdl.handle.net/2268/58459.

D'Otreppe, V., Boman, R., Ponthot, J.P., 2012. Generating smooth surface meshes from multi-region medical images. Int. J Numer. Meth. Biomed. Engng 28 (6-7), 642-660 http://hdl.handle.net/2268/96534.

Gnudi, G., Martini, F.M., Zanichelli, S., Volta, A., Bertoni, G., Del Bue, M., Borghetti, P., 2005. Incomplete humeral condylar fracture in two English Pointer dogs. Vet. Comp. Orthop. Traumatol. 18, 243-245.

Guille, A.E., Lewis, D.D., Anderson, T.P., et al., 2004. Evaluation of surgical repair of humeral condylar fractures using sel-compressing orthofix pins in 23 dogs. Vet. Surg. 33 , 314-322.

Kaderly, R.E., Lamothe, M., 1994. Incomplete humeral condylar fracture due to minor trauma in a mature cocker spaniel. J. Am. Anim. Hosp. Assoc. 28, 361-364.

Kaneps, A.J., Stover, S.M., Lane, N.E., 1997. Changes in canine cortical and cancellous bone mechanical properties following immobilization and remobilization with exercise. Bone 21, 419-423.

Keyak, J., Rossi, S.A., 2000. Prediction of femoral fracture load using finite element models: an examination of stress- and strain-based failure theories. J. Biomech. 33.

Knight, G., 1959. Internal fixation of the fractured lateral humeral condyle. Vet. Rec. 71, 667-668.
Marcellin-Little, D.J., Deyoung, D.J., Ferris, K.K., Berry, C.M., 1994. Incomplete ossification of the humeral condyle in spaniels. Vet. Surg. 23, 475-487.

Meyer-Lindenberg, A., Heinen, V., Fehr, M., et al., 2002. Incomplete ossification of the humeral condyle as the cause of lameness in dogs. Vet. Comp. Orthop. Traumatol. 3, 187-194.

Pieper, S., H., M., Kikinis, R., 2004. 3D Slicer. Proceedings of the IEEE International Symposium on Biomedical Imaging: From Nano to Macro Vol. 1, pp. 632-635.

Polikeit, A., Ferguson, S.J., Schawalder, P., 2007. Ellbogendysplasie beim Hund: FiniteElemente-Analyse/Elbow dysplasia in the dog: finite element analysis. Biomed. Tech./Biomed. Eng. 52, 308-314.

Ponthot, J.-P., Boman, R., Papeleux, L., 2000. Metafor, an in-house finite element software for large deformation analysis. http://www.ltas-mnl.ulg.ac.be/.

Robin, D., Marcellin-Little, D.J., 2001. Incomplete ossification of the humeral condyle in two Labrador Retrievers. J. Small Anim. Pract. 42, 231-234.

Rorvik, A., 1993. Risk factors for humeral condylar fractures the dog: a retrospective study. J. Small Anim. Pract. 277-282.

Rovesti, G., Fläckinger, M., Margini, M., Marcellin-Little, D.J., 1998. Fragmented coronoid process and incomplete ossification of the humeral condyle in a Rottweiler. Vet. Surg. 27.

Schebitz, H., Brunnberg, L., Vollmerhaus, B., Waibl, H., Beck, B., 1976. Zur Versorgung der Frakturen am Condylus humeri des Hundes. Br. J. Oral Maxillofac. Surg. 382-386.

Shigley, J., Mischke, C., Budynas, R., Liu, X., Gao, Z., 1989. Mechanical Engineering Design. McGraw-Hill, New York, p. 89.

Shuttleworth, A., 1938. Fracture of condyles of the humerus in the dog. Vet Jnl 94, 275.

Vannini, R., Olmstead, M.L., Smeak, D.D., 1988a. Humeral condylar fractures caused by minor trauma in 20 adult dogs. J. Am. Anim. Hosp. Assoc. 24, 355-362.

Vannini, R., Smeak, D.D., Olmstead, M.R., 1988b. Evaluation of surgical repair of 135 distal humeral fractures in dogs and cats. J. Am. Anim. Hosp. Assoc. 24, 537-545.

Vannini, R., Olmstead, M.L., Smeak, D.D. 2007. An epidemiological study of 151 distal humeral fractures in dogs and cats. J. Am. Anim. Hosp. Assoc. 24, 531-536. 